\title{
The necessity and development of a new modified scoring system for simultaneous detection of common bile duct stones in patients with planned laparoscopic cholecystectomy
}

Selçuk Gülmez¹, Necmi Kurt²

1Department of Gastroenterological Surgery, University of Health Sciences, Kartal Koşuyolu High Specialized Training and Research Hospital, Istanbul, Turkey 2Department of General Surgery, Kartal Dr. Lütfi Kırdar Training and Research Hospital, Istanbul, Turkey

Submitted: 28 July 2019

Accepted: 25 August 2019

Arch Med Sci Civil Dis 2019; 4: e89-e96

DOI: https://doi.org/10.5114/amscd.2019.89899

Copyright @ 2019 Termedia \& Banach

\section{Abstract}

Introduction: Choledocholithiasis is one of the undesirable consequences of gallbladder stones. Identifying such patients before cholecystectomy will prevent biliary leakage which develops secondarily to stones in the common bile duct (CBD). Scoring systems can be useful for prevention of complications.

Material and methods: A total of 201 patients with symptomatic cholecystolithiasis were prospectively evaluated with regards to stone presence in the CBD. These evaluations identified those patients suspected of having CBD stones. Parameters were established as clinically obstructive jaundice or acute cholangitis attack, biochemically abnormal liver functions tests (LFT), radiological identification of CBD stone or choledochal dilatation $(>8 \mathrm{~mm}$ ) as revealed by ultrasonography (USG). Residual stone controls were conducted through abdominal USG and LFT in the $3^{\text {rd }}$ and $6^{\text {th }}$ postoperative months. The patients' physical examinations were routinely conducted at each follow-up. Patients with common bile duct stones and those without were statistically compared as per the following data: age, sex, cholangitis, $\gamma$-glutamyl transpeptidase (GGT), alkaline phosphatase (ALP), Aspartate aminotransferase (AST), alanine aminotransferase (ALT), cholesterol, triglyceride, total bilirubin, direct bilirubin, CBD stone presence and choledochal size as revealed by USG.

Results: The parameters of our scoring system were: choledocholithiasis and choledochal dilatation in USG, total and direct bilirubin elevation, cholangitis episode in the last month, elevated AST, ALT, ALP, GGT, age $\geq 55$ and TG level. Twenty-seven patients had choledocholithiasis. With this scoring system, the minimum score required for preoperative ERCP was 9. The rate of simultaneous CBD stones was $13.4 \%$.

Conclusions: Selective cholangiography that uses this scoring system brings about more cost utility than that of its routine performance.

Key words: laparoscopic cholecystectomy, choledocholithiasis, endoscopic retrograde cholangiopancreatography, cholecystectomy, cholangitis.

\section{Introduction}

According to the National Institutes of Health Consensus Development Conference Statement of September 1992, the definitive treat-

\author{
Corresponding author: \\ Selçuk Gülmez \\ Department \\ of Gastroenterological \\ Surgery \\ University of \\ Health Sciences \\ Kartal Koşuyolu \\ High Specialized \\ Training and \\ Research Hospital \\ 34865 Istanbul, Turkey \\ Phone: +90 5530846215 \\ E-mail: selcukgulmez54@ \\ hotmail.com
}


ment of symptomatic gallstones, the prevalence of which is higher in middle-aged and older women, is laparoscopic surgery [1].

Common bile duct (CBD) stones prove to be one of the undesirable results of gallstones [2]. The coexistence rate of stones in the common bile duct of patients with gallstones varies as revealed by the results of different studies: $0.3 \%$ [3], $7-15 \%$ [4], 21.7\% [5]. The rate of CBD stone presence in patients with irregular liver function test (LFT) results is $43 \%$, while this rate falls to $7 \%$ in those with normal LFT results. Some studies have demonstrated that the rate of stone presence in the common bile duct was between $35 \%$ and $45 \%$ as demonstrated by endoscopic retrograde cholangiopancreatography (ERCP) performed prior to laparoscopic cholecystectomy [6].

CBD stones increase with age [2]. While the rate of stone coexistence in the common bile duct of patients under 60 years of age with laparoscopic cholecystectomy was $8-15 \%$, this figure is $15-60 \%$ in patients older than 60 years of age [1] The identification of such patients and accurate planning of how to remove their stones, if there are any, are significant matters [7]. The gold standard approach to detect coexisting CBD stones in patients with planned laparoscopic cholecystectomy still proves to be a controversial issue [8]. Identifying such patients before cholecystectomy will prevent biliary leakage which develops secondarily to stones in the common bile duct that could not be detected preoperatively and which account for major complications observed in the post-cholecystectomy period $[3,9,10]$. The elimination of CBD stones will also eliminate the chances of a cholangitis attack which may develop due to the presence of such stones. When this fact is taken into account, the major goal in the preoperative detection of CBD stones is to decrease the residual stone rate [11].

Routine preoperative cholangiography or laparoscopic choledochal exploration is not necessary in the presence of a surgical unit that performs ERCP [12]. The approach to detect stones in patients suspected of having CBD stones is to perform preoperative or perioperative cholangiography. The commonly held view of many centers in such a case is to perform ERCP before laparoscopic cholecystectomy. This, however, is recommended for a select group of patients and various studies have significantly underlined the fact that selective ERCP before laparoscopic cholecystectomy was an effective and safe method for the detection and elimination of CBD stones $[6,8,11$, 13]. These selection criteria are based on clinical, biochemical and radiological evaluations. There is no standard approach as of yet. The importance of having a scoring system following the standard- ization of these criteria increases day by day. Such scoring systems can be useful for both the prevention of biliary leakage that develops secondarily to residual CBD stones and reducing operative costs. Menezes et al. developed a scoring system to determine common bile duct stone. Accordingly, those with a score of 3 or higher were found to be at risk for CBD stone and ERCP was recommended. In this scoring system, ascending cholangitis, transaminases greater than double, dilatation of CBD or presence of stone in USG, each of them gets 3 or more points and it is indicated for ERCP. ERCP was applied to 55 patients with a score of 3 or higher and CBD stone was detected in only 23 of them. However, the fact that one parameter completes the cut off value for preoperative ERCP has led to an increase in the negative ERCP number [10].

The aim of this study was to prove the necessity of a scoring system in detecting CBD stones before laparoscopic cholecystectomy and to develop a new modified scoring system that could be rounded up with multiple parameters instead of a single one to ascertain the limit value necessary for preoperative ERCP.

\section{Material and methods}

Laparoscopy was performed on 225 out of 256 consecutive patients, while open surgery was performed on 31 patients older than 18 years of age because of symptomatic cholecystolithiasis between January 2002 and October 2003 at Dr. Lütfi Kirdar Kartal Training and Research Hospital's $3^{\text {rd }}$ Surgical Clinic. Laparoscopic procedures initiated for two patients were completed by switching to open surgery. Residual stone controls were conducted through abdominal ultrasonography (USG) and LFT in the $3^{\text {rd }}$ and $6^{\text {th }}$ postoperative months. The patients' physical examinations were routinely conducted at each follow-up. Twenty-two patients who could not be contacted for follow-ups or those who did not come in for follow-ups were excluded from the study along with 31 patients who received conventional procedures and 2 patients who switched to open surgery. Thus, a total of 201 patients were included in the study.

All the patients were prospectively evaluated with regards to stone presence in the common bile duct in the preoperative period. These evaluations identified those patients suspected of having CBD stones. This identification used certain selection criteria that were based on clinical, biochemical and radiological evaluations. Parameters were established as clinically obstructive jaundice or acute cholangitis attack, biochemically abnormal LFT results (transaminase and alkaline phosphatase (ALP)), radiological identification of CBD stone or choledochal dilatation $(>8 \mathrm{~mm})$ as re- 
vealed by USG. In the event that any of the said parameters was found to be positive, those patients were assessed to have CBD stone risk and ERCP was performed. In this way two groups were formed within the scope of our study: group 1: 27 patients with CBD stones determined through preoperative ERCP performed before laparoscopic cholecystectomy using selection criteria, group 2: 174 patients with no risk of CBD stones (no preoperative ERCP) as revealed by selection criteria within the same period. Patients in groups 1 and 2 were statistically compared within the scope of a new modified scoring system based on the one developed by Menezes et al. [10]. This statistical analysis took into account data pertaining to serum triglyceride (TG), cholesterol levels, age and sex $[14,15]$ which pose stone formation risks having considered the determination of common bile duct diameter and CBD stone detection through USG, LFT results, and the fact that CBD stones mostly originate from gallstones. The results of such analyses led to the development of a new scoring system. Statistically insignificant parameters were excluded from the system. Further, all significant biochemical parameters incorporated quantitative values.

LFT analyses included aspartate aminotransferase (AST SGOT), alanine aminotransferase (ALT, SGPT), $\gamma$-glutamyl transferase (GGT) and alkaline phosphatase (ALP) along with total and direct bilirubin serum levels. Our scoring system was based on the quantitative value of billirubin instead of jaundice. The reason for this is that the term jaundice corresponds to the total bilirubin elevation, but the patient with a bilirubin level just above the normal value a cannot bear the same risk as CBD stone with whose billirubin levels are so much higher than this.

These tests were conducted at most 1 month prior to laparoscopic cholecystectomy or ERCP. Active cholangitis attack and high total bilirubin levels (as confirmed by laboratory data and independent of another cause) within the last month were sought. Jaundice and cholangitis attacks that the patients suffered from prior to this period were not taken into account in the scoring.

Stone detection in the common bile duct was not included in the scoring system unless stone and choledochal sizes were given in millimeters due to the spontaneous passing of small-size CBD stones and the fact that USG is a performer-dependent method. USG imaging of all patients was performed by two specialist radiologists, while their ERCPs were performed by two general surgeons above the learning threshold, and their laparoscopic cholecystectomy procedures were performed by or accompanied by three general surgeons also above the learning threshold. Each patient's leukocyte and amylase values were tested at least once following the ERCP procedure.

Patients with common bile duct stones and those without were statistically compared as per the following data: age, sex, cholangitis, GGT, ALP, ALT, AST, cholesterol, triglyceride, total bilirubin, direct bilirubin, CBD stone presence and choledochal size as revealed by USG. Consecutive numeric values were used for each statistically significant numeric parameter to determine starting from which value they would be eligible for use in our scoring system. Sensitivity and specificity values were obtained according to this. Figures that had the highest sensitivity and specificity values were included in the scoring system. Following the determination of significant parameters' weights according to one another (significance ranking), each parameter was scored according to such weight. All the patients were scored according to this ranking, and sensitivity and specificity were determined for consecutive scores. The highest value obtained as a result of this process became the critical limit value to be proposed for preoperative ERCP.

Ethics committee approval was received for the present study from Dr. Lütfi Kirdar Kartal Training and Research Hospital's Board of Ethics.

\section{Statistical analysis}

SPSS 10.0 for Windows was used for the statistical analyses of the data collected within the scope of the study. Descriptive statistical methods (mean, standard deviation) were used to assess study data along with Student's $t$-test for the comparison of quantitative values. The $\chi^{2}$ test and Fisher's exact $\chi^{2}$ test were used for the comparison of quantitative values. Diagnostic screening tests (sensitivity, specificity, positive predictive value, negative predictive value) were also used. Weighting of the parameters was conducted by discriminant analysis. The cut-off value for the total score was ascertained by ROC analysis. The results were presented with the $95 \%$ confidence interval, while statistical significance was set at $p<0.05$.

\section{Results}

Table I presents the summary of mean, standard deviation and significance $(p)$ values of the laboratory, radiological and clinical data of all patients.

Sex and serum cholesterol levels, ascertained to be statistically insignificant parameters as revealed by the results of this analysis, were excluded from the study. The next step determined from which numeric level the statistically significant numeric parameters would be included in the scoring system. The highest sensitivity and specificity values were found, and the figures to be used in 
Table I. The mean, standard deviation and $p$-values for all parameters

\begin{tabular}{|c|c|c|c|c|c|}
\hline \multirow[t]{3}{*}{ Parameter } & \multicolumn{4}{|c|}{ Common bile duct stone } & \multirow{3}{*}{$\begin{array}{c}P \text {-value } \\
\text { univariate }\end{array}$} \\
\hline & \multicolumn{2}{|c|}{ Yes $(n=13)$} & \multicolumn{2}{|c|}{ No $(n=174)$} & \\
\hline & Mean & $\begin{array}{l}\text { Standard } \\
\text { deviation }\end{array}$ & Mean & $\begin{array}{l}\text { Standard } \\
\text { deviation }\end{array}$ & \\
\hline Age & 61.93 & 14.99 & 51.51 & 13.64 & 0.01 \\
\hline ALP & 836.44 & 725.73 & 216.77 & 96.05 & 0.0001 \\
\hline GGT & 446.63 & 411.45 & 36.91 & 38.11 & 0.0001 \\
\hline SGOT & 207.22 & 187.29 & 27.29 & 23.62 & 0.0001 \\
\hline SGPT & 216.56 & 172.82 & 31.83 & 48.81 & 0.0001 \\
\hline Total bilirubin & 7.05 & 4.19 & 0.66 & 0.53 & 0.0001 \\
\hline Direct bilirubin & 5.39 & 3.55 & 0.21 & 0.26 & 0.0001 \\
\hline Cholesterol & 193.81 & 62.76 & 174.75 & 51.57 & 0.084 \\
\hline Triglyceride & 172.33 & 47.28 & 129.71 & 61.93 & 0.0001 \\
\hline CBD diameter on USG [mm] & 12.32 & 4.44 & 3.86 & 1.35 & 0.0001 \\
\hline Parameter & $n$ & $\%$ & $n$ & $\%$ & $P$-value \\
\hline \multicolumn{6}{|l|}{ Cholangitis: } \\
\hline Yes & 14 & 51.9 & - & - & 0.0001 \\
\hline No & 13 & 48.9 & 174 & 100 & \\
\hline \multicolumn{6}{|l|}{ CBD stone on USG: } \\
\hline Yes & 19 & 70.4 & - & - & 0.0001 \\
\hline No & 8 & 29.6 & 174 & 100 & \\
\hline \multicolumn{6}{|l|}{ Gender: } \\
\hline Female & 18 & 66.7 & 126 & 72.4 & 0.538 \\
\hline Male & 9 & 33.3 & 48 & 27.6 & \\
\hline
\end{tabular}

the scoring system, which are presented in Table II, were achieved.

Following the weighting of statistically significant parameters according to one another to be used in the scoring system, it was found that the most valuable parameter to show CBD stone was the presence of stone in the common bile duct on USG, while the least valuable parameter was the serum triglyceride level. It was observed that the figures expressing weighting were concentrated in 3 categories and the scoring to be used in the system was conducted having taken this fact into account. Values between 0 and 0.200 were allocated to category 1 , while those between 0.201 and 0.400 were allocated to category 2 and those at and above 0.401 were allocated to category 3 . According to this classification, each parameter forming the lowest category was assigned 1 point, while each parameter forming category 2 was given 2 points and parameters forming category 3 were given 3 points each (Table III).
A new modified scoring system that could be used to identify patients with CBD stone risk before laparoscopic cholecystectomy was developed as a result of this scoring (Table IV).

The cut-off point, which would signify a limit value for preoperative ERCP, was ascertained by scoring all patients for consecutive scores through this newly developed scoring system. This assessment used sensitivity and specificity values corresponding to each score. The minimum necessary score for preoperative ERCP was then determined based on figures that had the best values. Score 9, which had the highest sensitivity and specificity values, proved to be the one that we would recommend for preoperative ERCP for CBD stone risk (Table V).

While no complications were observed in patients with ERCP within the scope of assessments covering clinical observation and biochemical tests, only a couple of patients had increases in non-specific amylase levels. Cannulation was successfully conducted for all patients and their sphincterot- 
Table II. Statistical data of all significant parameters

\begin{tabular}{|c|c|c|c|c|c|}
\hline Parameter & Sensitivity (\%) & Specificity (\%) & $\begin{array}{l}\text { Positive predic- } \\
\text { tive value }(\%)\end{array}$ & $\begin{array}{l}\text { Negative predic- } \\
\text { tive value (\%) }\end{array}$ & Accuracy (\%) \\
\hline Age $\geq 55$ & 66.66 & 62.64 & 21.68 & 92.37 & 63.18 \\
\hline$A L P \geq 350$ & 85.18 & 94.25 & 69.69 & 97.62 & 93.03 \\
\hline $\mathrm{GGT} \geq 100$ & 81.48 & 93.10 & 64.70 & 97.01 & 91.54 \\
\hline SGOT $\geq 90$ & 70.37 & 98.28 & 86.36 & 95.53 & 94.53 \\
\hline $\mathrm{SGPT} \geq 80$ & 88.88 & 95.40 & 75.0 & 98.22 & 94.53 \\
\hline $\begin{array}{l}\text { Total bilirubin } \\
\geq 2.5 \mathrm{mg} / \mathrm{dl}\end{array}$ & 92.59 & 97.7 & 86.20 & 98.84 & 97.01 \\
\hline $\begin{array}{l}\text { Direct bilirubin } \\
\geq 2.0 \mathrm{mg} / \mathrm{dl}\end{array}$ & 88.88 & 99.43 & 96.0 & 98.30 & 98.01 \\
\hline $\begin{array}{l}\text { CBD diameter } \\
\text { on USG } \geq 7 \mathrm{~mm}\end{array}$ & 92.59 & 96.55 & 80.64 & 98.82 & 96.02 \\
\hline $\mathrm{TG} \geq 150 \mathrm{mg} / \mathrm{dl}$ & 74.07 & 66.67 & 25.64 & 94.31 & 67.66 \\
\hline CBD stone on USG & 70.37 & 100.0 & 100.0 & 95.60 & 96.02 \\
\hline Cholangitis & 51.81 & 100 & 100 & 93.05 & 93.53 \\
\hline
\end{tabular}

Table III. Formation of points within the scoring system

\begin{tabular}{|llcc|}
\hline Significant parameter & Weight & Category & Score \\
\hline Triglyceride & 0.074 & Category 1 & \\
\hline Age & 0.790 & & \\
\hline GGT & 0.228 & & \\
\hline ALP & 0.234 & & \\
\hline SGPT & 0.250 & Category 2 & \\
\hline SGOT & 0.264 & \\
\hline Cholangitis & 0.295 & \\
\hline Direct bilirubin & 0.414 & \\
\hline Total bilirubin & 0.419 & \\
\hline CBD dilatation on USG & 0.433 & 0.438 & \\
\hline CBD stone on USG & & \\
\hline
\end{tabular}

omy procedures were performed. 2 out of 27 patients with CBD stones had biliary pancreatitis.

Preoperative cholangiography for selective patients instead of routine performances is quite cost-effective. To determine this select group of patients, however, necessitates a scoring system. In our study, the rate of stone presence in the common bile duct as determined by ERCP before laparoscopic cholecystectomy in symptomatic patients with gallstones was $13.4 \%$.

\section{Discussion}

Gallstones are highly prevalent in society, particularly in women. Although they are commonly seen, $60-80 \%$ of gallstones are asymptomatic.
Today it is recommended that asymptomatic gallstones should merely be followed up and surgical management is recommended for symptomatic patients or those with complications [16]. The gold standard therapy for symptomatic cholelithiasis, on the other hand, is elective laparoscopic cholecystectomy [1].

The rate of stone presence in the common bile duct in patients with gallstones is at a considerable level and they mainly originate from such gallstones. When the results of LFT are irregular in a patient, this figure reaches quite high levels [6]. The co-existence of cholelithiasis and CBD stone increases in direct proportion to aging [1]. Preoperative identification of such patients can prevent possible postoperative complications. Cholangiog- 
Table IV. Data used in our scoring system

\begin{tabular}{|c|c|c|}
\hline \multicolumn{2}{|l|}{ Parameter } & \multirow{2}{*}{$\begin{array}{c}\text { Score } \\
1\end{array}$} \\
\hline Age & $\geq 55$ & \\
\hline & $<55$ & 0 \\
\hline \multirow[t]{2}{*}{ TG } & $\geq 150$ & 1 \\
\hline & $<150$ & 0 \\
\hline \multirow[t]{2}{*}{ GGT } & $\geq 100$ & 2 \\
\hline & $<100$ & 0 \\
\hline \multirow[t]{2}{*}{ ALT } & $\geq 90$ & 2 \\
\hline & $<90$ & 0 \\
\hline \multirow[t]{2}{*}{ AST } & $\geq 80$ & 2 \\
\hline & $<80$ & 0 \\
\hline \multirow[t]{2}{*}{ ALP } & $\geq 350$ & 2 \\
\hline & $<350$ & 0 \\
\hline \multirow{2}{*}{$\begin{array}{l}\text { Total bilirubin } \\
{[\mathrm{mg} / \mathrm{dl}]}\end{array}$} & $\geq 2.5$ & 3 \\
\hline & $<2.5$ & 0 \\
\hline \multirow{2}{*}{$\begin{array}{l}\text { Direct bilirubin } \\
{[\mathrm{mg} / \mathrm{dl}]}\end{array}$} & $\geq 2.0$ & 3 \\
\hline & $<2.0$ & 0 \\
\hline \multirow{2}{*}{$\begin{array}{l}\text { CBD diameter } \\
\text { on USG [mm] }\end{array}$} & $\geq 7$ & 3 \\
\hline & $<7$ & 0 \\
\hline \multirow{2}{*}{$\begin{array}{l}\text { Cholangitis } \\
\text { attack within } \\
\text { the last month }\end{array}$} & $(+)$ & 3 \\
\hline & $(-)$ & 0 \\
\hline \multirow{2}{*}{$\begin{array}{l}\text { CBD stone on } \\
\text { USG }\end{array}$} & $(+)$ & 3 \\
\hline & $(-)$ & 0 \\
\hline
\end{tabular}

raphy for select patients is the current modality approach when cost effectiveness and septic complications are taken into account. Risky patients who would receive selective cholangiography can be identified by certain selection criteria. These criteria include clinically obstructive jaundice and/or cholangitis attack, radiological determination of stone in the CBD and/or CBD dilation on USG and abnormal liver function test results as revealed by laboratory examinations [7, 12, 13, 17-19]. Although these criteria are widely accepted in the identification of patients at risk for CBD stones, they vary according to many studies as well. In a study by Csendes et al. [20], the authors added a different criterion, namely cystic duct diameter larger than $4 \mathrm{~mm}$, to these criteria and suggested an increased risk for CBD stone in the event that the USG CBD diameter was larger than $7 \mathrm{~mm}$. Mo et al. [17], on the other hand, stated that they had performed preoperative ERCP in patients with CBD diameters larger than $8 \mathrm{~mm}$ and had taken recent pancreatitis history into account. Further, Himal [21] argued that preoperative ERCP was not indicated in moderate pancreatitis of biliary origin. Unlike others, Masci et al. [13] have set the CBD diameter limit on USG at more than $10 \mathrm{~mm}$ for preoperative ERCP. In a study conducted with 870 patients' CBD results on USG, Hunt [22] reported that as the CBD diameter went up so would the chances of stone presence but CBD stones could also be seen in patients with normal CBD diameters. One can offer more examples and, as is seen, the selection of patients for cholangiography varies across physicians. The adaptation of this situation in the form of a scoring system that can be implemented for each physician and patient with no extra cost would definitely provide great convenience and advantage for everyone. The utilization of these data can reduce the number of negative ERCP procedures [19].

Not only is selective preoperative ERCP effective for detecting CBD stones $[8,17,18]$ but also it creates cost utility [23]. In their study, Rijna et al. performed selective preoperative ERCP for 42 out of 328 symptomatic patients with gallbladders and the results of their study revealed that $30 \mathrm{pa}-$ tients had CBD stones [18]. In another study by Mo et al. [17] the authors stated that they performed selective preoperative ERCP for 247 out of 1,630 patients with symptomatic cholelithiasis following the implementation of selection criteria and found that 146 of these patients had CBD stones. Sarli et al. reported in their study covering their 10-year treatment experience in patients with cholecystocholedocholithiasis that the strategy to be adopted in these cases was performing laparoscopic cholecystectomy following endoscopic sphincterotomy and selective preoperative ERCP [8]. The evaluation of CBD stone risk factors to be used in the scoring system would prevent routine

Table V. Some of the total score values used to determine the cut-off value for the scoring system to be used to identify patients for preoperative ERCP

\begin{tabular}{|lcccc|}
\hline Total score & Sensitivity (\%) & Specificity (\%) & $\begin{array}{c}\text { Positive predictive } \\
\text { value (\%) }\end{array}$ & $\begin{array}{c}\text { Negative predictive } \\
\text { value (\%) }\end{array}$ \\
\hline 4 & 100 & 90.23 & 61.36 & 100 \\
\hline 5 & 100 & 95.98 & 79.41 & 100 \\
\hline 9 & 100 & 98.28 & 90.00 & 100 \\
\hline
\end{tabular}


cholangiography [20]. It is clear that performing preoperative ERCP for each patient suspected of having CBD stones based on various criteria instead of a scoring system will not create cost utility. The need to standardize this process is quite evident.

Performing selective ERCP instead of a routine one does not bring about a significant increase in mortality and morbidity rates in relation to residual stones following laparoscopic cholecystectomy [24]. The further post-ERCP laparoscopic cholecystectomy protocol reduces the need for other procedures and the length of hospitalization [7].

Table VI presents the scoring system developed by Menezes et al. [10]. This study was based on qualitative data and set the minimum score required for preoperative ERCP at 3. Preoperative ERCP was performed for 55 patients in the said study by using the scoring system, yet only $23 \mathrm{pa}$ tients were found to have CBD stones. In the same study, any of the conditions that showed that the results of liver function tests were greater than double or CBD dilatation or stone presence was seen on USG rounded up the required score for preoperative ERCP. Although the risk of stone presence in the event of CBD dilatation increases, the risk of stone presence in the $C B D$ is not overwhelmingly high in cases with only CBD dilatation while other parameters are normal. This fact can merely lead to an increase in the number of negative ERCPs and costs. Moreover, the USG CBD diameter limit used in the scoring has not been revealed. Additionally, liver function tests have been generalized which could lead to confusion. Indeed, liver function tests incorporate the serum levels of many variable parameters such as AST, ALT, GGT, ALP, total and direct bilirubin [25]. Not only is our newly developed scoring system simple, but also it is based on quantitative data. It can easily be used in symptomatic patients with gallstones by all physicians. It also serves as a guide to clinicians in identifying which patients are preoperative ERCP candidates. We further believe that our newly developed scoring system prevents unnecessary ERCP procedures after rounding up the score by a few variables or the failure to identify CBD stones in the preoperative period having set the score high, both of which were among our goals within the scope of this study.

The results of our study revealed that the rate of CBD stones in patients with gallstones was $13.4 \%$, and this rate is $35-40 \%$ with increasing age in some studies [6]. We, therefore, recommend a scoring system that is required before laparoscopic cholecystectomy and suggest that preoperative ERCP should be performed for patients
Table VI. The scoring system developed by Menezes et al.

\begin{tabular}{|c|c|c|}
\hline Factor & Criteria & Score \\
\hline \multirow[t]{2}{*}{ Gender } & Female & 0 \\
\hline & Male & 1 \\
\hline \multirow[t]{2}{*}{ Age } & $<55$ & 0 \\
\hline & $\geq 55$ & 1 \\
\hline \multirow[t]{3}{*}{ Jaundice } & Absent & 0 \\
\hline & Resolved & 1 \\
\hline & Current & 2 \\
\hline \multirow[t]{3}{*}{ Cholangitis } & Absent & 0 \\
\hline & Resolved & 1 \\
\hline & Current & 2 \\
\hline \multirow{3}{*}{$\begin{array}{l}\text { Liver function } \\
\text { tests }\end{array}$} & $N$ & 0 \\
\hline & $\begin{array}{l}\text { Greater than } \\
\text { normal but less } \\
\text { than double }\end{array}$ & 2 \\
\hline & $\begin{array}{l}\text { Greater than } \\
\text { double }\end{array}$ & 4 \\
\hline \multirow{2}{*}{$\begin{array}{l}\text { CBD dilatation on } \\
\text { USG }\end{array}$} & Normal & 0 \\
\hline & Dilated & 3 \\
\hline \multirow[t]{2}{*}{ CBD stone on USG } & Absent & 0 \\
\hline & Present & 3 \\
\hline
\end{tabular}

with a score of 9 or higher instead of routine preoperative ERCP.

In conclusion, preoperative ERCP is an effective and common method used in the diagnosis and treatment of CBD stones and selective cholangiography that uses this scoring system brings about more cost utility than that of its routine performance.

\section{Conflict of interest}

The authors declare no conflict of interest.

\section{References}

1. NIH consensus conferance. Gallstones and laparoscopic cholecystectomy. JAMA 1993; 269: 1018-24.

2. Maingot's Abdominal Operations. $9^{\text {th }}$ Edition. Zinner MJ, Schwartz SI, Ellis H (eds). Vol. 2. Appleton \& Lange, International Edition, Connecticut 1990; 1337-478.

3. Sungler P, Heinerman PM, Mayer F, Boeckl O. Laparoscopic cholecystectomy in cholecysto-choledocholithiasis. "Therapeutic splitting" or conventional surgical procedure? Chirurg 1993; 64: 1012-7.

4. Damjanov I, Linder J. Anderson's Pathology. $10^{\text {th }}$ Edition, Mosby, St. Louis 1996; 1869-75.

5. Bezzi M, Silecchia G, Orsi F, et al. Complications after laparoscopic cholecystectomy. Coordinated radiologic, endoscopic, and surgical treatment. Surg Endosc 1995; 9: 29-36. 
6. Franceschi D, Brandt C, Margolin D, et al. The management of common bile duct stones in patients undergoing laparoscopic cholecystectomy. Am Surg 1993; 59: 525-32.

7. Morris PJ, Wood WC. Oxfort Textbook and Surgery. 2nd Edition. Vol. 2. Oxfort Univercity Press, New York 2000; 1663-710.

8. Sarli L, Iusco DR, Roncoroni L. Preoperative endoscopic sphincterotomy and laparoscopic cholecystectomy for the management of cholecystocholedocholithiasis: 10year experience. World J Surg 2003; 27: 180-6.

9. Sarli L, Pietra N, Franzé A, et al. Routine intravenous cholangiography, selective ERCP, and endoscopic treatment of bile duct stones before laparoscopic cholecystectomy. Gastrointest Endosc 1999; 50: 200-8.

10. Menezes N, Marson LP, DeBeaux AC, Muir IM, Auld CD. Prospective analysis of a scoring system to predict choledocholithiasis. Br J Surg 2000; 87: 1176-81.

11. Schafer M, Krahenbuhl L, Buchler MW. Diagnosis and treatment of common bile duct stones: a current review and the Berne concept. Schweiz Med Wochenschr 1999; 129: 624-30.

12. Charfare H, Cheslyn-Curtis S. Selective cholangiography in 600 patients undergoing cholecystectomy with 5 -year follow-up for residual bile duct stones. Ann R Coll Surg 2003; 85: 167-73.

13. Masci E, Fanti L, Mariani A, et al. Selection criteria for pre-operative endoscopic retrograde cholangiography and endoscopic-laparoscopic treatment of biliary stones. Eur J Gastroenterol Hepatol 1999; 11: 781-4.

14. The Rome Group for Epidemiology and Prevention of Cholelithiasis. The epidemiology of gallstone disease in Rome, Italy. Part II. Factors associated with the disease (GREPCO). Hepatology 1988; 8: 907-13.

15. Tang WH. Serum and bile lipid levels in patients with and without gallstones. J Gastroenterol 1996; 31: 823-7.

16. Cameron JL. Current Surgical Therapy. $7^{\text {th }}$ edition. Mosby Inc, St. Louis 2001; 399-480.

17. Mo LR, Chang KK, Wang CH, Yau MP, Yang TM. Preoperative endoscopic sphincterotomy in the treatment of patients with cholecystocholedocholithiasis. J Hepatobiliary Pancreat Surg 2002; 9: 191-5.

18. Rijna H, Kemps WG, Eijsbouts Q, Meuwissen SG, Cuesta MA. Preoperative ERCP approach to common bile duct stones: results of a selective policy. Dig Surg 2000; 17: 229-33.

19. Nataly Y, Merrie AE, Stewart ID. Selective use of preoperative endoscopic retrograde cholangiopancreatography in the era of laparoscopic cholecystectomy. ANZ J Surg 2002; 72: 186-9.

20. Csendes A, Burdiles P, Diaz JC, et al. Prevalence of common bile duct stones according to the increasing number of risk factors present. A prospective study employing routinely intraoperative cholangiography in 477 cases. Hepatogastroenterology 1998; 45: 1415-21.

21. Himal HS. Common bile duct stones: the role of preoperative, intraoperative, and postoperative ERCP. Semin Laparosc Surg 2000; 7: 237-45.

22. Hunt DR. Common bile duct stones in non-dilated bile ducts? An ultrasound study. Australas Radiol 1996; 40 221-2.

23. Thumbe VK, Dorricott NJ. Investigation of bile ducts before laparoscopic cholecystectomy. JSLS 1999; 3: 23-5.

24. Thornton DJ, Robertson A, Alexander DJ. Laparoscopic cholecystectomy without routine operative cholangiography does not result in significant problems related to retained stones. Surg Endosc 2002; 16: 592-5.
25. Uomo G, Rabitti PG, Laccetti M, et al. The role of clinical, biochemical and echographic data in identifying the biliary pathogenesis of acute pancreatitis. Recenti Prog Med 1992; 83: 206-9. 